\title{
EFFECTS OF DEFOLIATION BY CATERPILLARS ON TREE GROWTH.
}

\author{
BY F. H. FOSTER, CLAREMONT, N. H.
}

IN the year 1897 Clisiocampa disstria appeared in parts of Central and Western New Hampshire in great numbers and caused serious damage to forest and shade trees, especially to sugar maples. The insects appeared in still greater numbers in 1898 and 1899 , when many trees in the infested districts were completely defoliated. Many old trees were killed outright and others fell into a state of hopeless decrepitude.

At the request of Mr. W. F. Fiske of the Entomology Division of the U. S. Department of Agriculture, who at the time of the Clisiocampa outbreak was assistant Entomologist at the New Hampshire Experiment Station, and who spent some time in studying the parasites of this insect, the writer recently procured a section of the trunk of a live sugar maple about eight inches in diameter which disclosed some interesting history.

The sugar orchard from which this specimen was taken had suffered very severely. Many trees in it have died and been cut up for fuel.

The last four annular rings in this tree corresponding to the seasons of I900, 1901, 1902 and 1903 were the thickest rings in the tree, averaging one eighth inch making a total increase in diameter for the four years since the abatement of the Clisiocampa pest, of one inch. The rings next preceding, however, corresponding to the years of more or less complete defoliation, were thinner than any others in the tree and were somewhat indistinct and confused, suggesting a doubling more or less perfect of the rings in those years.

This doubling might be the result of a checking of the growth during early summer followed by another period of formation of wood tissue in late summer when the tree had put forth another partial crop of leaves. Allowing two of these rings for a year, the section plainly shows that the amount of wood formed annually during the years of the pest (1897, '98 and '99) was less than half the amount formed in the succeeding years or with two or three exceptions. in any of the preceding fifty or more years of the trees' existence. Many trees in this orchard showed damage by borers, but the one examined was selected for its apparent freedom from injury from this cause in order not to have the case complicated by damage from other causes than Clisiocampa disstria. 

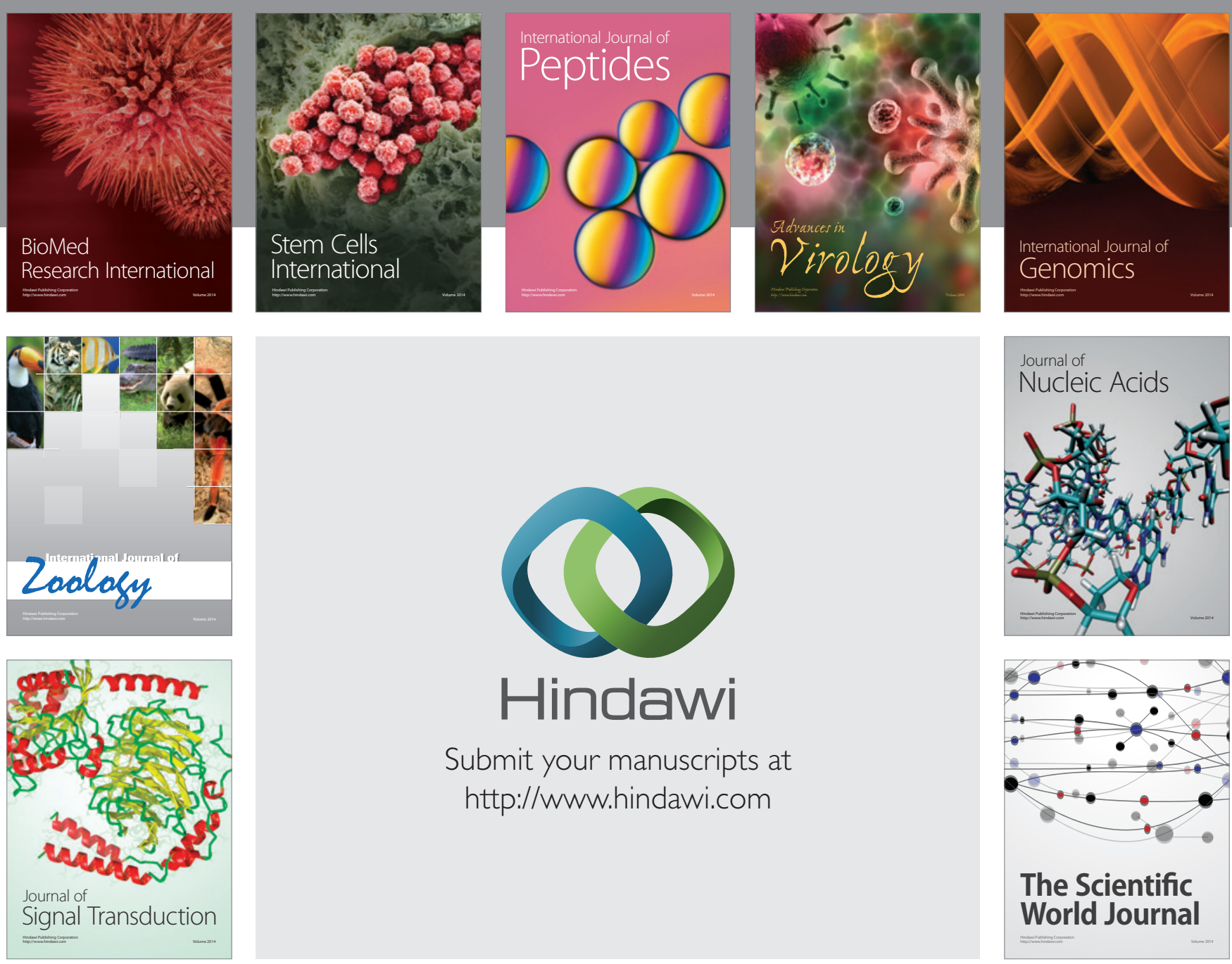

Submit your manuscripts at

http://www.hindawi.com
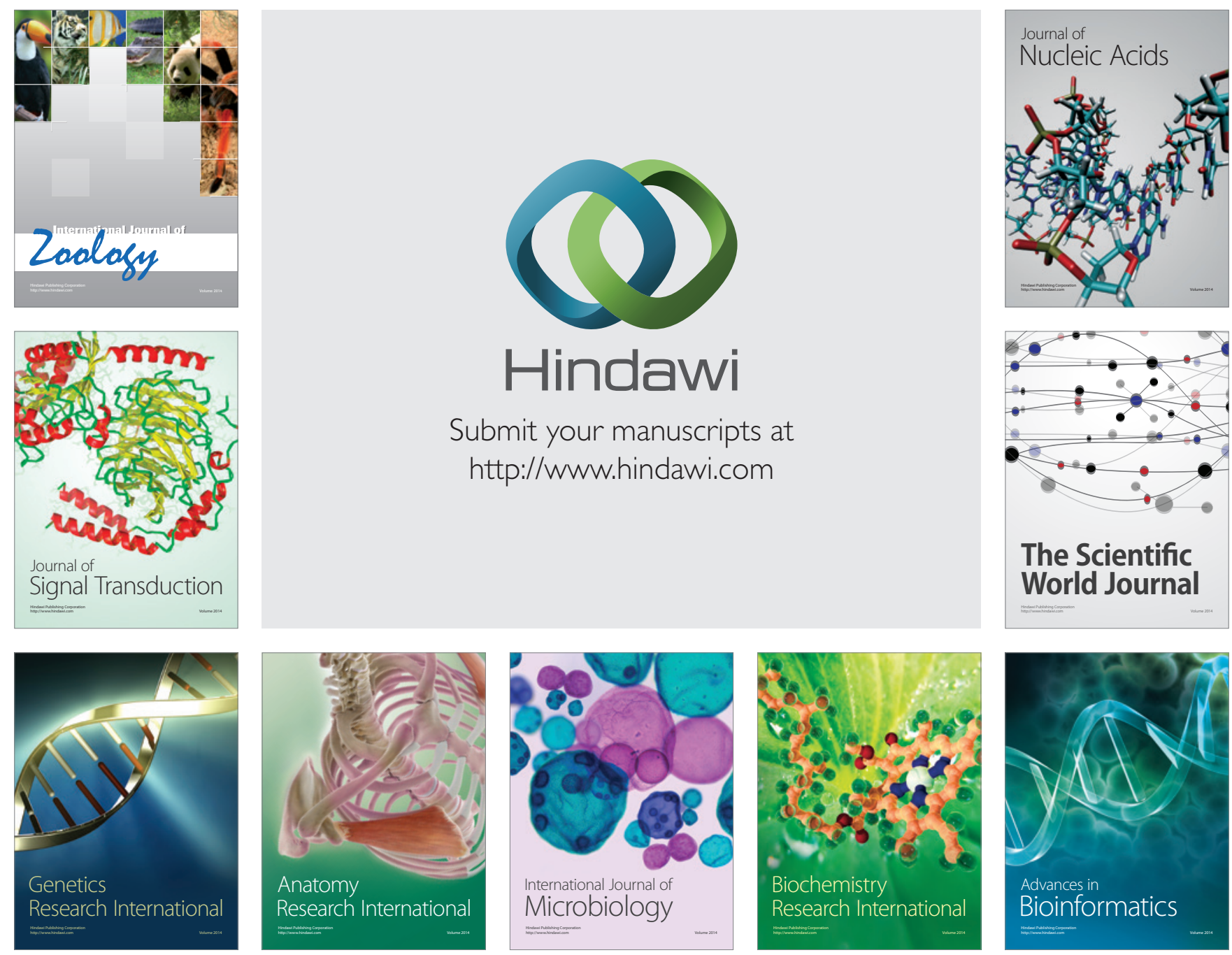

The Scientific World Journal
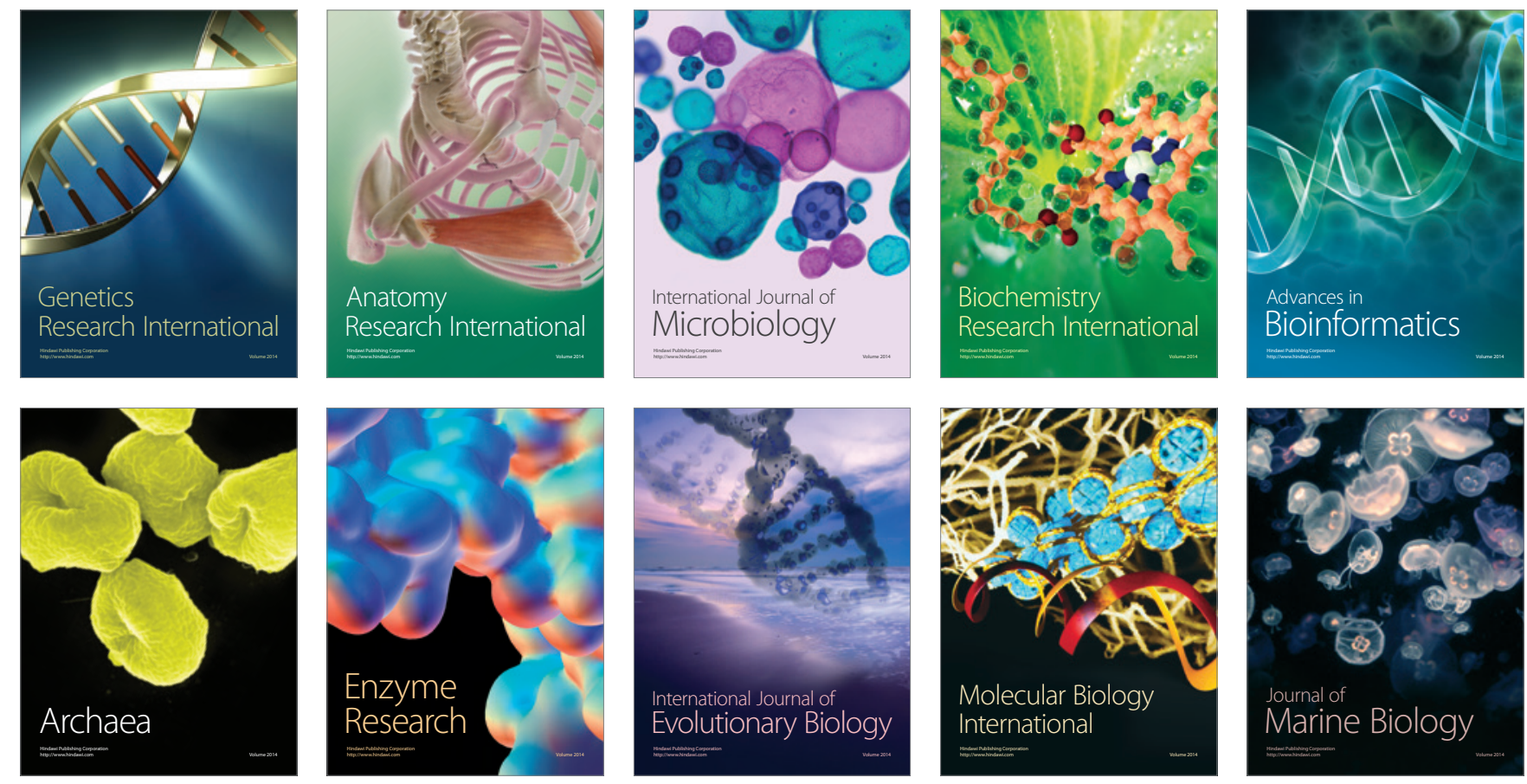